\title{
EFFECTS OF METAL INERT GAS WELDING PARAMETERS ON SOME MECHANICAL PROPERTIES OF AUSTENITIC STAINLESS STEEL IN ACIDIC ENVIRONMENT
}

\author{
I. M. B. Omiogbemi ${ }^{1}{ }^{*}$, D. S. Yawas ${ }^{2}$, I. M Dagwa ${ }^{3}$ and F. G. Okibe ${ }^{4}$ \\ 1, 2, Department of Mechanical EngineEring, Ahmadu Bello University, ZARia, KAduna STATE, NigERIA

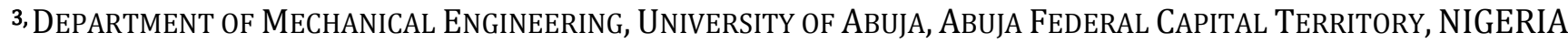

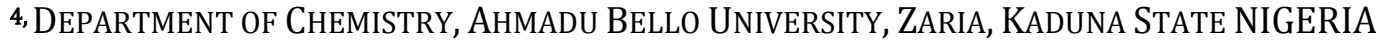 \\ E-mailaddresses.10miogbemi@yahoo.com, ${ }^{2}$ dyawas@yahoo.com,33dagwaim@gmail.com, ${ }^{4}$ fgokibe@gmail.com
}

\begin{abstract}
The purpose of the present study is to investigate the effects of metal inert gas (MIG) welding parameters on the mechanical properties (hardness, tensile and impact) of type 304 austenitic stainless steel (ASS) immersed in 0.5M hydrochloric acid at ambient temperature. The MIG welding was applied to 3mm thick ASS. The dimensions of the samples were $50 \mathrm{~mm} \times 15 \mathrm{~mm} \times 3 \mathrm{~mm}$ and $120 \mathrm{~mm} \times 15 \mathrm{~mm} \times 3 \mathrm{~mm}$ rectangular bars each for impact, hardness and tensile tests and for immersion in the medium. Design Expert Software, Scanning Electron Microscopy (SEM), Rockwell Hardness Test, Monsanto Tensometer and Izod Impact Test were used to determine the interactions of parameters, microstructural analysis and optimal performances of the parameters respectively. Experimental results indicate that tensile strength increased with increase in welding parameters from $120 \mathrm{MN} / \mathrm{m}^{2}$ to $133 \mathrm{MN} / \mathrm{m}^{2}$ at speed of $40 \mathrm{~cm} / \mathrm{min}$ and current of 110. when the properties are compared with varying weld parameters adopted in joint's weld operations, there was a pattern displayed among the weld parameters with $C_{3}\left(19.7 \mathrm{HRA}, 203 \mathrm{~N} / \mathrm{mm}^{2}\right.$ and $\left.19.7 \mathrm{~J}\right)$ and $C_{4}(14.9 \mathrm{HRA}$, $189 \mathrm{~N} / \mathrm{mm}^{2}$ and 14.9J) consistently coming out as the parameter producing an ASS weld joint with the best mechanical properties of hardness, tensile and impact strength. Surface corrosion deposit composition was analyzed with the SEM paired with energy dispersive spectrometer (EDS) to ascertain microstructural behavior of the material.
\end{abstract}

Keywords- MIG, Mechanical Destructive tests, Current, Speed, ASS, SEM, HCl.

\section{INTRODUCTION}

Metal Inert Gas (MIG) welding is a process that has been commercially available for around 60 years. The basic operation of the MIG process occurs when an electrical arc is established and maintained between a base material and a continuously feed wire electrode. Both the arc and the weld pool are protected from atmospheric contamination by a shield of inert (non-reactive) gas, which is delivered through a nozzle that is concentric with the welding wire guide tube [1].

MIG also known as gas metal arc welding (GMAW) is the most common industrial welding process, preferred for its versatility, speed and the relative ease of adapting the process even to robotic automation. It is used extensively by the sheet metal industry and by extension, the automobile industry [2].

The increasing high demand on stainless steel usage in industry as a result of rapid growth, combined with difficulties in production routes and fluctuating raw materials prices of major alloying additions such as nickel, molybdenum, and chromium have stimulated engineering companies and fabricators to develop alternative grades to the commercial austenitic stainless steels such as 304,310 , and 316 , with attractive corrosion and mechanical properties as well as stable prices [3].

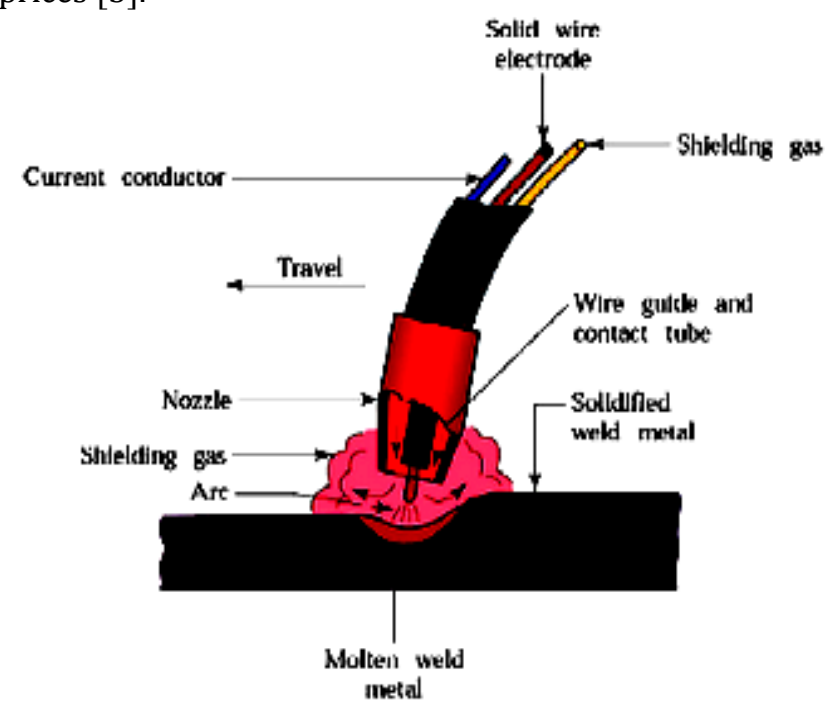

Figure 1: Gas Metal Arc Welding operation [2]. 
Welding of austenitic stainless steels with high demand of sound mechanical properties require a high degree of control of welding parameters, consumable and thermo mechanical condition with regard to their effect on mechanical and metallurgical properties [4].

Corrosion remains one of the most severe limitations for the use of various steels in the chemical and petrochemical industries. Millions of dollars are lost each year because of corrosion. Much of this loss is due to the corrosion of iron and steel [5].

Shivashanmugan, et al [6] investigated the microstructure and mechanical properties and found that hardness is lower in the weld metal as compared to parent metal and heat affected zone. Yan, et al [7] investigated the mechanical properties and microstructure of stainless steel and results showed that the microstructure consists of delta ferrite and gamma ferrite phase. Gharibshahiyan, et al [8] investigated that with the increase in voltage, the grain size number decreased in case of low carbon welded steel using inert gas welding. Omiogbemi, [4] investigated the effects of gas metal arc welding parameters on the mechanical and corrosion behavior of ASS in some environments using design expert software.

Corrosion is the deterioration of a material by a chemical attack or reaction under the influence of the surrounding environment. Corrosion is a continuous process which could be difficult to control and terminate [9].

Many research findings have proved that improper techniques employed in welding austenitic stainless steels may lead to serious consequences of the welded structures $[10,11]$.

Failure as a result of poor mechanical properties and poor corrosion resistance have also found their place in annals of times, from household equipment to industrial structures such as railways, road bridges, storage tanks and ocean liners. One of such failures is the corrosion cracking of a grade 304 stainless steel pipe improperly seam welded and meant for the conveying of glucose solution in Illinois USA [12]. Many other failures have proved to be welding prone or propagated. However, it is important to investigate the effects of metal inert gas welding parameters on the mechanical properties of ASS in hydrochloric acid medium.

This study is targeted to examine MIG welding parameters on the mechanical behavior of a welded ASS immersed in hydrochloric acid medium.

\section{MATERIALS AND METHODS}

\subsection{Materials}

The material used in this study is $3 \mathrm{~mm}$ diameter ASS locally sourced from Kaduna State, Nigeria and its chemical composition was determined which is shown in table 1. Other materials were: Stainless steel electrode wire of $0.9 \mathrm{~mm}$, Acetone, Distill water, $\mathrm{SiC}$ abrasive paper grit 400, 600 and 800, Hydrochloric acid (HCl) 0.5 Molar concentration. The equipment used were: MIG Welding machine, Digital Weighing Balance, Grinding Machine, impact testing machine: MODEL; 6701, Capacity 120 FT.LB, Rockwell Hardness Testing Machine, Monsanto Tensometer, "Type W" Guillotine shear: EDWARDS, MODEL 3.25/300 and Phenom ProX Scanning Electron Microscope.

\subsection{Methods}

A $50 \mathrm{~mm} \times 15 \mathrm{~mm} \times 3 \mathrm{~mm}$ and a $120 \mathrm{~mm}$ x $15 \mathrm{~mm}$ x $3 \mathrm{~mm}$ dimensions of ASS samples were cut to produce a plain face sample for butt wedding for tensile test and hardness test respectively, leaving a root opening of $2 \mathrm{~mm}$. the same dimension of hardness sample was used for impact test with a notch of $0.3 \mathrm{~mm}$. The butt welding method was implemented as shown in the sample preparation in figure 2. Single pass was used in the welding operation for each of the specimen. Both welded and non-welded specimens were cleaned of dirt and oil using paper grit $(400,600$ and 800) and acetone according to ASTM standard. A digital weighing balance was used to determine the mass of the samples before and after immersion in the medium and then analysed using the design expert software. The X-ray florescence (XRF) test was used to determine the ASS structure.

\subsection{Experimental Design of Welding Parameters}

Three factors were selected to investigate the Mechanical properties of welded ASS in hydrochloric medium. Speed (S), Current (I) and constant Voltage (E) that are represented as $\mathrm{A}, \mathrm{B}$ and $\mathrm{C}$ respectively, are the welding parameters and the voltage was kept constant during the welding operation. The corrosion behaviour was examined by varying these factors at two levels $\left(2^{2}\right)$, high $(+1)$ and low $(-1)$ with a centre point (0) in the experimental runs (Tables 2 and 3 ) to ascertain the rate of deterioration. The interactions between these factors were evaluated and optimization was carried out using three dimensional plots according to Okibe [13].

Table 1: Composition of austenitic stainless steel

\begin{tabular}{|l|l|l|l|l|l|l|l|l|l|}
\hline element & $\mathrm{C}$ & $\mathrm{S}$ & $\mathrm{Ni}$ & $\mathrm{Mo}$ & $\mathrm{Mn}$ & $\mathrm{Cr}$ & $\mathrm{P}$ & $\mathrm{Si}$ & $\mathrm{Fe}$ \\
\hline Wt \% & 0.12 & 0.01 & 8.34 & 0.18 & 1.36 & 20.12 & 0.03 & 0.54 & $\mathrm{Bal}$ \\
\hline
\end{tabular}




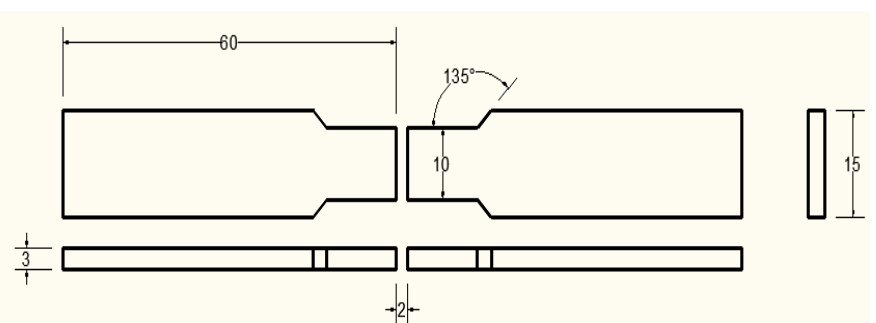

a

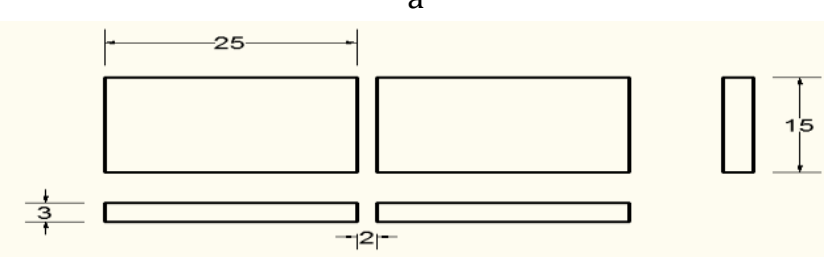

b
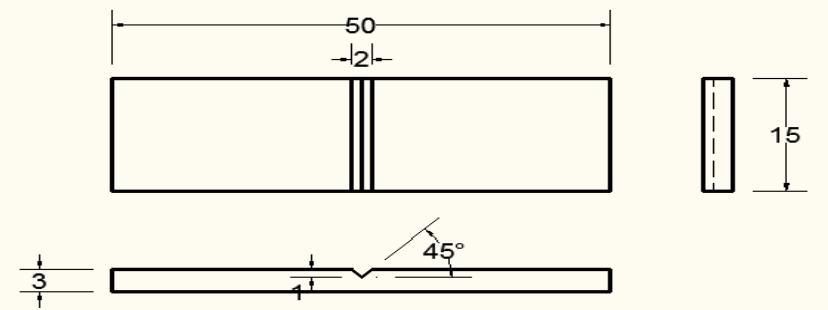

c

Figure 2: Standard Joint Preparations samples for tensile, hardness and impact tests in $\mathrm{mm}$.

Table 2: Factors and levels used for the welding parameters;

\begin{tabular}{lccccc}
\hline \multirow{2}{*}{$\begin{array}{l}\text { Welding } \\
\text { parameters }\end{array}$} & \multirow{2}{*}{ Symbol } & \multirow{2}{*}{ Unit } & & \multicolumn{3}{c}{ Factor Levels } \\
\cline { 4 - 6 } & & & Low & Centre & High \\
& & $(-)$ & $(0)$ & $(+)$ \\
\hline Speed & S & cm/min & 20 & 30 & 40 \\
Voltage & E & Volts & 230 & 230 & 230 \\
Current & I & Amp & 90 & 100 & 110 \\
\hline
\end{tabular}

Table 3: Design matrix for welding parameters of ASS in $\mathrm{HCl}$ medium

\begin{tabular}{ccccc}
\hline Std & Run & A: Speed $(\mathrm{cm} / \mathrm{min})$ & B. Current (A) & C: Voltage(V) \\
\hline 1 & 1 & 20 & 90 & 230 \\
3 & 2 & 20 & 110 & 230 \\
5 & 3 & 30 & 100 & 230 \\
4 & 4 & 40 & 110 & 230 \\
2 & 5 & 40 & 90 & 230 \\
6 & 6 & 30 & 100 & 230 \\
\hline
\end{tabular}

Design Expert software 6.0.6 was used to generate the experimental runs and for the statistical analysis of weight loss in milligram of the ASS in the $\mathrm{HCl}$ solution in an interval of eight (8) for forty (40) days as shown in Figure 3 and Figure 4.

\subsection{Weight Loss Measurement}

$1 \mathrm{dm}^{3}$ of volumetric flask containing solution of $20.89 \mathrm{~cm}^{3}$ of $\mathrm{HCl}$ as prepared in accordance with Yawas, [14] was used to immerse the samples for 40 days. The samples were taken out of the acid medium after every 8 days, wash with distilled water and acetone, air dried and reweighed. The digital weighing balance machine with a sensitivity of $0.0001 \mathrm{~g}$ was used to assess the weight loss of the test samples.

\subsection{Hardness Test}

The Rockwell hardness testing method consists of indenting the test material with a diamond indenter, in the form of a right pyramid with a square base at an angle of $120^{\circ}$ between opposite faces subjected to a minor load of $10 \mathrm{~kg}$ to a major load of $60 \mathrm{~kg}$. The full load is normally applied for 10 to15 seconds. The two diagonals of the indentation left in the surface of the material after removal of the load are measured using a microscope and their average calculated. Before the test, the mating surfaces of the indenter, plunger rod and the test samples were thoroughly cleaned by removing the dirt, scratches and oil.

\subsection{Tensile Test}

The ASS samples were subjected to tensile tests in accordance with ASTM E8 Standard Method. These tests were carried out using the Monsanto Tensometer, Type "W" with a capacity of $20 \mathrm{kN}$. The ASS samples were machined using a milling machine into a standardized shape of the sample with a central reduced section for tensile test with a dimension of $120 \mathrm{~mm} \times 15 \mathrm{~mm} \times 3 \mathrm{~mm}$ as shown in Figure 2.

\subsection{Impact Test}

The reliability of a material can be determined, by measuring its resistance to fracture, either ductile or brittle of fracture toughness [15]. The impact tests was conducted in accordance with ASTM A370 "Standard Method and Definitions for Mechanical Testing of Steel Products". The samples of ASS sheet was dimensioned as $50 \mathrm{~mm} \times 15 \mathrm{~mm} \times 3 \mathrm{~mm}$ for impact test. These samples were cut into two halves and welded along the cut section using MIG machine with stainless steel electrode core wire. V- notches of $0.3 \mathrm{~mm}$ depth was made on the samples and were tested for toughness using the Izod impact testing machine and the results obtained were recorded in joules.

\subsection{Scanning Electron Microscope of ASS}

The welded and the non-welded austenitic stainless steels were viewed using Phenom ProX scanning electron microscope (SEM) with a magnification between 500x to 5000x. The samples for investigation were prepared in accordance with the specifications of 
the machine. The setup was then loaded into the column which is connected to the monitor in a closed loop for which control and feedback are actualized. The lableling of samples are shown in Table 4.

\section{Table 4: Sample Labelling}

\begin{tabular}{|c|c|}
\hline $\begin{array}{l}\text { Sample } \\
\text { C }\end{array}$ & $\begin{array}{l}\text { Control sample not welded and not immersed } \\
\text { (As received) }\end{array}$ \\
\hline Sample & Sample welded with $20 \mathrm{~cm} / \mathrm{min}$ speed and $90 \mathrm{~A}$ \\
\hline $\mathrm{C}_{1}$ & oltage of $230 \mathrm{~V}$ \\
\hline Sample & le welded with $20 \mathrm{~cm} / \mathrm{min}$ speed and \\
\hline $\mathrm{C}_{2}$ & current at constant voltage of $230 \mathrm{~V}$ \\
\hline Sample & le welded with $30 \mathrm{~cm} / \mathrm{min}$ speed and \\
\hline $\mathrm{C}_{3}$ & current at constant voltage of $230 \mathrm{~V}$ \\
\hline Sample & Sample welded with $40 \mathrm{~cm} / \mathrm{min}$ speed and \\
\hline $\mathrm{C}_{4}$ & $110 \mathrm{~A}$ current at constant voltage of $230 \mathrm{~V}$ \\
\hline Samp & Sample welded with $40 \mathrm{~cm} / \mathrm{min}$ speed and $90 \mathrm{~A}$ \\
\hline $\mathrm{C}_{5}$ & current at constant voltage of $230 \mathrm{~V}$ \\
\hline
\end{tabular}

\section{RESULTS AND DISCUSSIONS}

\subsection{Evaluation of Factorial Design for the Responses of Welding Parameters}

Table 5 show the variation of the selected welding parameters (factors) affecting the behaviour of ASS in $0.5 \mathrm{M}$ concentration of $\mathrm{HCl}$ medium and the corresponding weight loss in milligrams obtained after each experimental run was performed on the welded ASS samples immersed for 40 days in an interval of 8 days. The results show that experimental run four (4) gave the least weight loss values for sixteen (16) days and forty (40) days as $0.0546 \mathrm{mg}$ and $0.0759 \mathrm{mg}$ respectively at a welding speed of $40 \mathrm{~cm} / \mathrm{min}$, welding current of 110 Amperes at a constant voltage of 230 volts. This implies that experimental run four (4) gave the least average weight loss value. This further shows that in a corrosive $\mathrm{HCl}$ medium, ASS is vulnerable to corrosion. While experimental run five (5) and two (2) gave the highest average weight loss values. This implies that at low current and low speed, poor weldment of ASS was obtained. The analysis of variance (ANOVA) is shown in Table 6. From the results of the ANOVA, model F-value of 63.66 implies that the model is significant. There is only $1.55 \%$ chance that a "Model F-Value" could occur due to error terms. Values of "Prob $>$ F" less than 0.0500 indicate model terms are significant. Here, $\mathrm{B}$ and $\mathrm{AB}$ are significant model terms while $\mathrm{A}$ is not significant. The "Curvature F-value" of 63.66 implies that there is significant curvature in the design model.

The results from Figures 3 and 4 show that at constant voltage of $230 \mathrm{~V}$, a varied speed from $20 \mathrm{~cm} / \mathrm{min}$ to $40 \mathrm{~cm} / \mathrm{min}$ and a varied current from $90 \mathrm{Amp}$ to $110 \mathrm{Amp}$, weight losses for sixteen (16) days and forty (40) days were obtained as follows; For sixteen (16) days, these values were obtained; 9.94\% (C+, B-, $\mathrm{A}+), 5.52 \%(\mathrm{C}+$, $\mathrm{B}+, \mathrm{A}+), 7.05 \%\left(\mathrm{C}+, \mathrm{B}-, \mathrm{A}^{-}\right)$and $7.73 \%\left(\mathrm{C}+, \mathrm{B}+, \mathrm{A}^{-}\right)$. While for forty (40) days, we have $32.56 \%\left(C+, B_{-}^{-}, A+\right)$, 5.17\% (C+, B+, A+), 8.31\% (C+, B-, A-) and 16.38\% $(\mathrm{C}+, \mathrm{B}+, \mathrm{A}-)$. It was concluded from the analysis that corrosion susceptibility of ASS structure is more visible at 40 days immersion than in 16 days as observed in the percentage corrosion of the steel.

Table 5: Experimental Design for welding parameters of ASS in HCl medium used

\begin{tabular}{c|c|c|c|c|c|c|c|c|c}
\hline Std & Run & $\begin{array}{c}\text { A: Speed } \\
(\mathrm{cm} / \mathrm{min})\end{array}$ & $\begin{array}{c}\text { B: Current } \\
(\mathrm{A})\end{array}$ & $\begin{array}{c}\mathrm{C}: \\
\text { Voltage } \\
(\text { volts })\end{array}$ & $\begin{array}{c}\mathrm{WL}_{8} \\
(\mathrm{mg})\end{array}$ & $\begin{array}{r}\mathrm{WL}_{16} \\
(\mathrm{mg})\end{array}$ & $\begin{array}{r}\mathrm{WL}_{24} \\
(\mathrm{mg})\end{array}$ & $\begin{array}{c}\mathrm{WL}_{32} \\
(\mathrm{mg})\end{array}$ & $\begin{array}{c}\mathrm{WL}_{40} \\
(\mathrm{mg})\end{array}$ \\
\hline 1 & 1 & 20 & 90 & 230 & 0.0608 & 0.0699 & 0.0795 & 0.1103 & 0.1073 \\
3 & 2 & 20 & 110 & 230 & 0.0708 & 0.0767 & 0.1047 & 0.1309 & 0.1880 \\
5 & 3 & 30 & 100 & 230 & 0.0485 & 0.0752 & 0.0901 & 0.1005 & 0.0971 \\
4 & 4 & 40 & 110 & 230 & 0.0470 & 0.0546 & 0.0970 & 0.0974 & 0.0759 \\
2 & 5 & 40 & 90 & 230 & 0.0631 & 0.0988 & 0.1356 & 0.2151 & 0.3498 \\
6 & 6 & 30 & 100 & 230 & 0.0480 & 0.0786 & 0.1412 & 0.1016 & 0.1181 \\
\hline
\end{tabular}

Table 6: ANOVA for the factorial model for speed and current at a constant voltage for HCI medium.

\begin{tabular}{l|l|l|l|l|l|l}
\hline Source & Sum of Squares & DF & Mean Square & F Value & Prob>F & Remark \\
\hline Model & $1.011 \times 10^{-3}$ & 3 & $3.372 \times 10^{-4}$ & 63.66 & 0.0155 & Significant \\
A & $1.156 \times 10^{-5}$ & 1 & $1.156 \times 10^{-5}$ & 2.18 & 0.2776 & Not Significant \\
B & $3.497 \times 10^{-4}$ & 1 & $3.497 \times 10^{-4}$ & 66.02 & 0.0148 & Significant \\
AB & $6.502 \times 10^{-4}$ & 1 & $6.502 \times 10^{-4}$ & 122.77 & 0.0080 & Significant \\
Residual & $1.059 \times 10^{-5}$ & 2 & $5.297 \times 10^{-6}$ & & & \\
Lack of Fit & $4.813 \times 10^{-6}$ & 1 & $4.813 \times 10^{-6}$ & 0.83 & 0.5291 & Not Significant \\
Pure Error & $5.780 \times 10^{-6}$ & 1 & $5.780 \times 10^{-6}$ & & & \\
Cor Total & $1.022 \times 10^{-3}$ & 5 & & & & \\
\hline
\end{tabular}




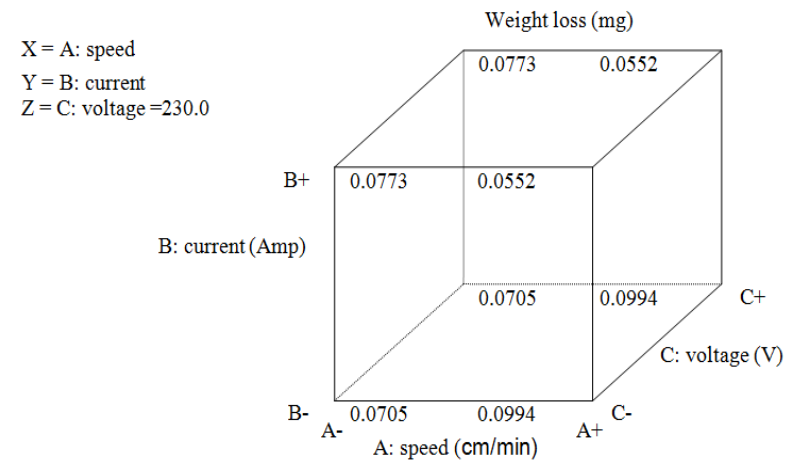

Figure 3: Cube plot for ASS immersed in HCl for 16 days

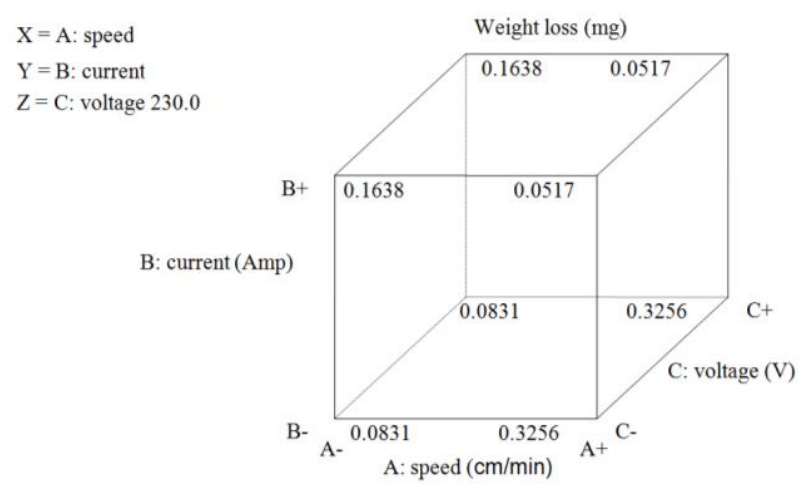

Figure 4: Cube plot for ASS immersed in HCl for 40 days

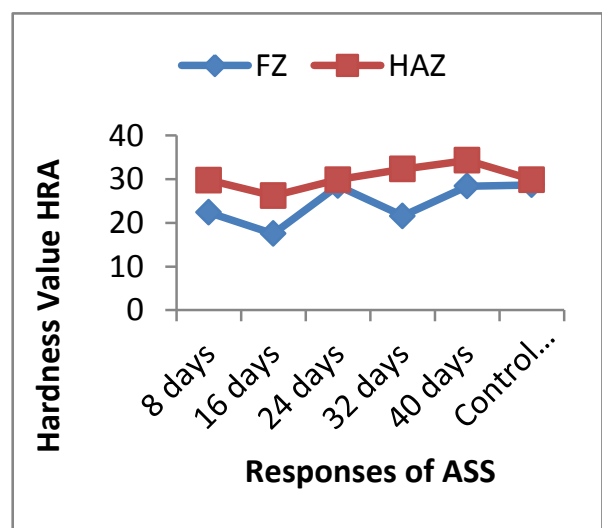

(a)

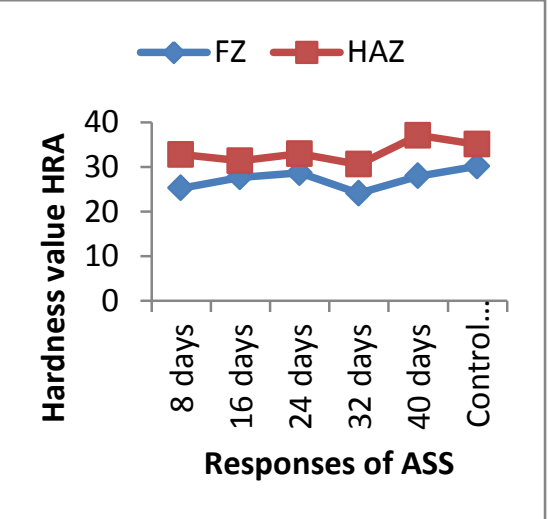

(b)

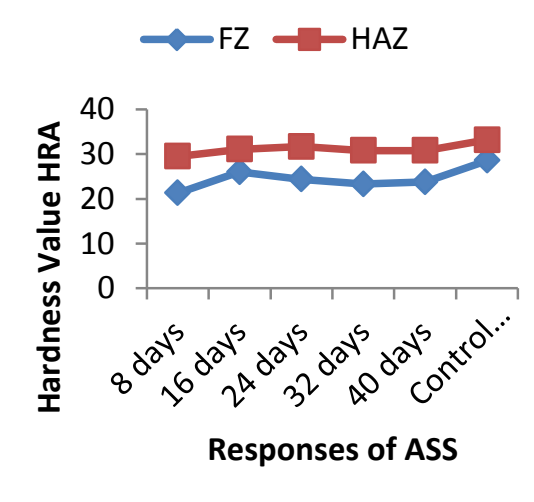

(c)

Figure 5: Comparison of hardness values of ASS immersed in HCl medium with control sample.

\subsection{Hardness Properties of ASS Structure}

Figure $5 \mathrm{a}, \mathrm{b}$ and $\mathrm{c}$ shows that the hardness value is high in the heat affected zone of the material than at the weld zone. This could be due to the residual stresses at the HAZ caused by the heat generated during welding. It was observed that the foreign ASS (welded but not immersed) produced a relatively high average value of hardness test. However, of the different intervals of immersions, 40 days of immersion produced a relatively high hardness value than other intervals. A similar trend was observed in the result of the hardness test conducted in relation to tensile test results. The variation in the hardness values of the ASS samples also agreed with observations made by Mishra et al, [16] and Kock, [17]. They showed that hardness is a function of grain size of the weldment and the integrity of the welded joints.

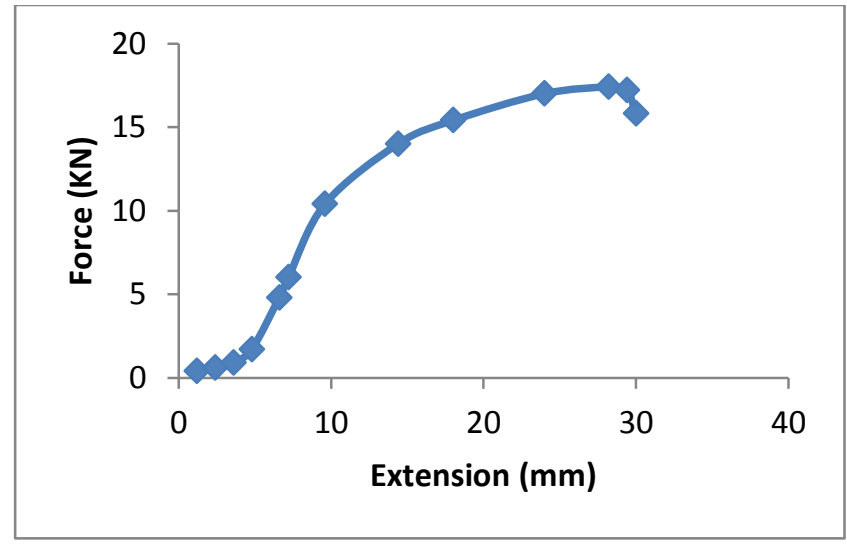

(a)

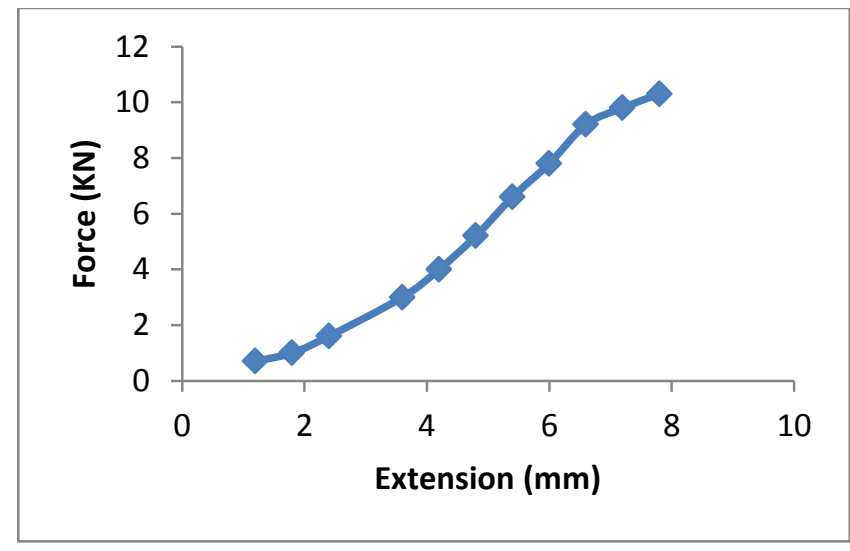

(b)

Figure 6: Load-Extension Curve of tensile test on (a) unwelded ASS (C) and (b) welded ASS (C $C_{4}$ ) 


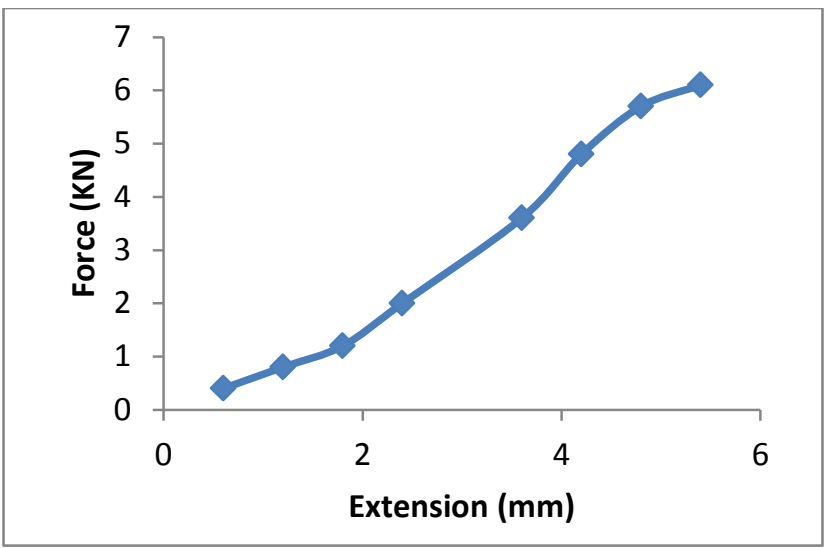

(a)

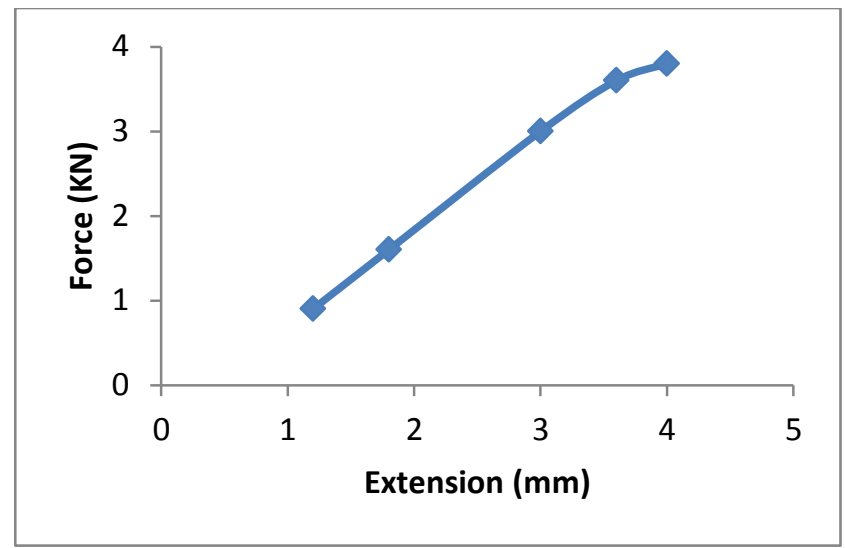

(b)

Figure 7: Load-Extension of tensile test on (a) welded ASS ( $\left.C_{2}\right)$ in $\mathrm{HCl}$ for 16 days and (b) on welded ASS $\left(C_{5}\right)$ in $\mathrm{HCl}$ for 40 days

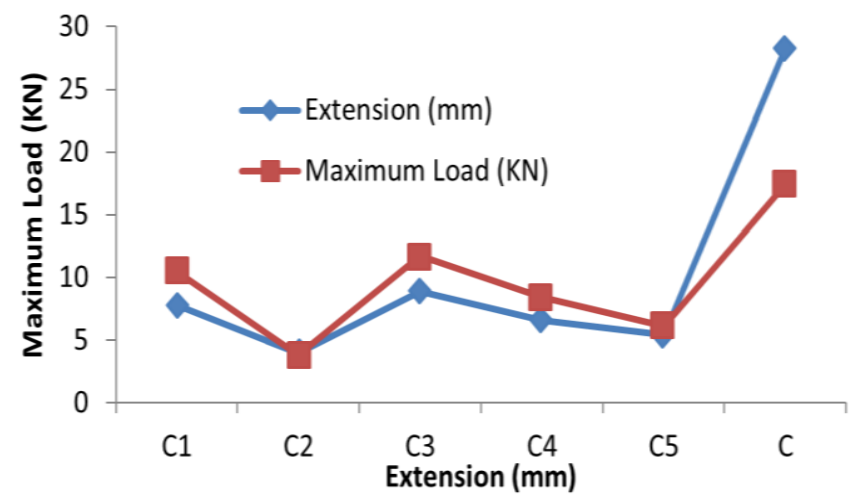

Figure 8: Load-Extension of tensile test on the samples of ASS immersed in HCl medium

\subsection{Tensile Properties of ASS Structure}

Figures $6 \mathrm{a}$ and $\mathrm{b}$ show the variation of load against extension of the tensile test of the weldment of ASS structure. It was observed generally that with a gradual increase in load, there is a corresponding increase in extension of the specimen; that is the extension produced is directly proportional to the load. This continues until the maximum load is reached. At this point of maximum load, a neck is formed. The reduced area was not able to sustain the load being applied, hence the specimen finally fractured at this new point which is called the breaking load point.

It can be seen from figure $7 \mathrm{a}$ and $\mathrm{b}$ that samples immersed in $0.5 \mathrm{M}$ of $\mathrm{HCl}$ medium for 40 days has lower tensile strength compared to samples immersed for 16 days of exposure time. This implies that $\mathrm{HCl}$ medium has greater corrosive effect on the integrity of the welded joint when subjected to tensile stress. This may be due to the aggressiveness of the chloride ion $\left(\mathrm{Cl}^{-}\right)$in the medium [18]. Also it is noted from figure 8 that there is a gradual decrease in the tensile strength of the immersed
ASS in $\mathrm{HCl}$ with increasing exposure time but high tensile strength observed with the control sample.

\subsection{Impact Properties of ASS Structure}

Figures $9 \mathrm{a}, \mathrm{b}$ and 10 show the results of the impact test conducted on some samples (control samples, welded and immersed samples and also unwelded samples). It was observed generally that the sample $\mathrm{C}_{3}$ among others has the highest impact energy.

From the figures, it was seen that samples immersed in $0.5 \mathrm{M}$ of $\mathrm{HCl}$ acid medium from 8 days to 40 days, (sample $\mathrm{C}_{3} \mathrm{C}_{5}$ and $\mathrm{C}$ ) were the parameters that produced weldment with the highest absorbed energy. Also, the results showed that samples that are welded and immersed in $\mathrm{HCl}$ for 16 days, produced high impact energy than those immersed in $\mathrm{HCl}$ for 40 days. This could be due to the high deterioration effect of the steel in $\mathrm{HCl}$ medium. It could also be as a result of the coarse microstructure in the MIG process. The variation in the impact strength is in agreement with the variation of their elongation at failure during tensile and hardness tests carried out. The result obtained from this test is in agreement with those obtained by Bonnefois et al., [19].

\subsection{Correlation of Hardness, Tensile and Impact Strength Tests}

It was observed from the mechanical destructive tests carried out on the ASS structure immersed in acidic medium used for this study that when the properties are compared with varying weld parameters adopted in the weldment operations, there was a pattern displayed among the weld parameters with $\mathrm{C}_{3}$ (19.7HRA, $203 \mathrm{~N} / \mathrm{mm}^{2}$ and $\left.19.7 \mathrm{~J}\right)$ and $\mathrm{C}_{4}\left(14.9 \mathrm{HRA}, 189 \mathrm{~N} / \mathrm{mm}^{2}\right.$ and 14.9J) consistently coming out as the parameter producing an ASS weld joint with the best mechanical properties of hardness, tensile and impact strength. 


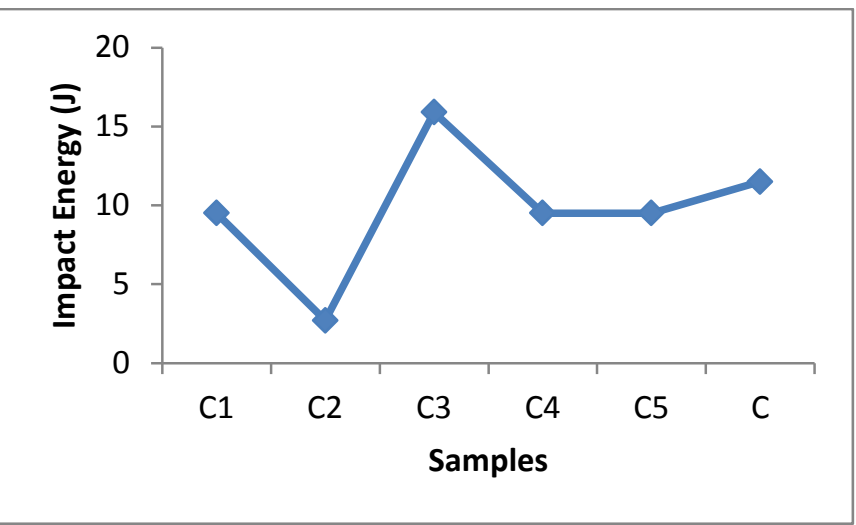

(a)

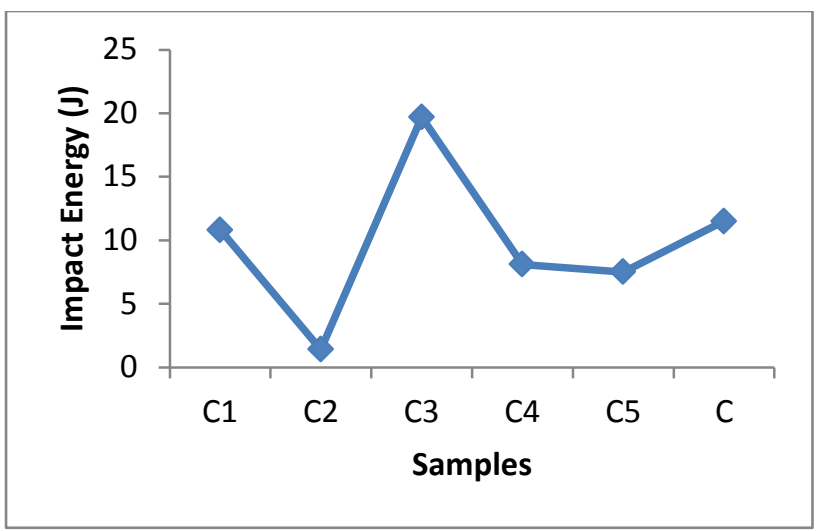

(b)

Figure 9: Impact Energy for ASS immersed in HCl for (a) 16 days and (b) 40 days as compared to controls

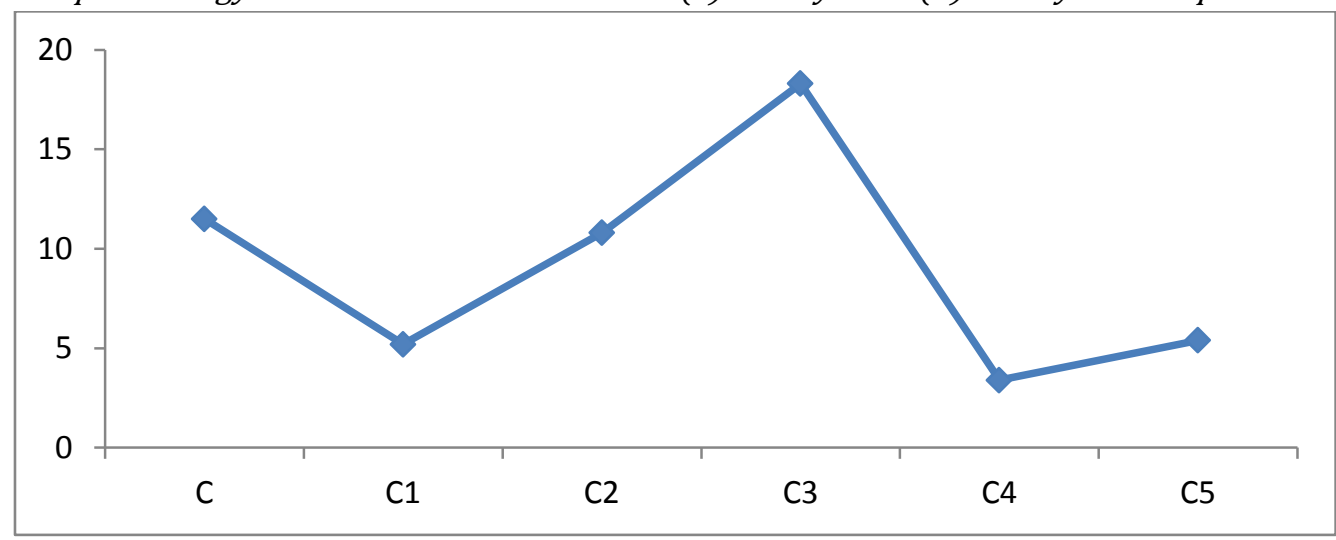

Figure 10: Impact test for the control; welded and unwelded control of ASS
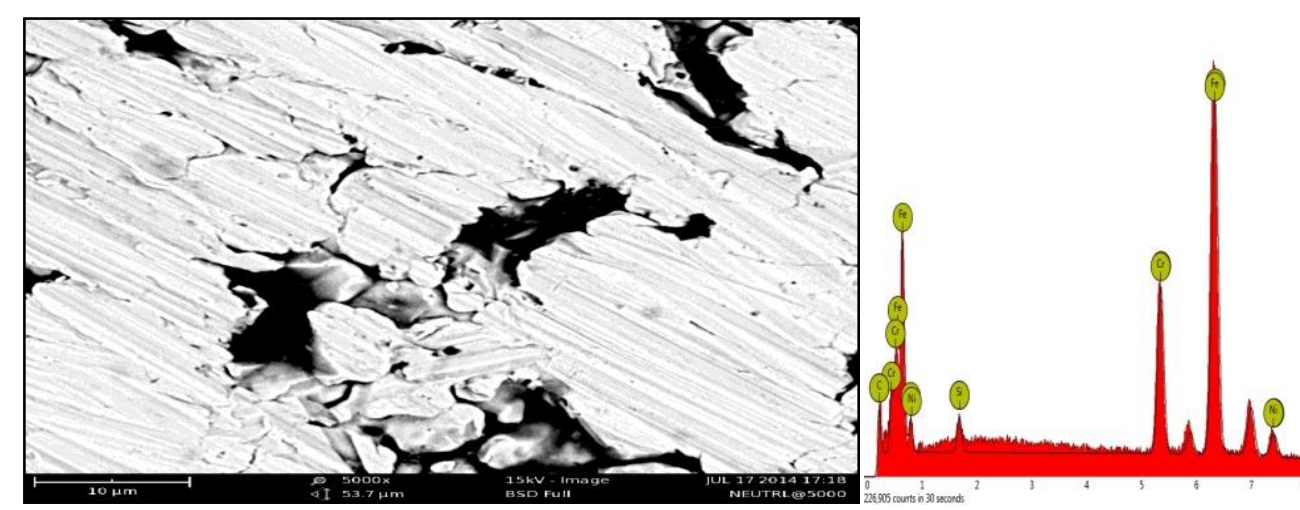

Figure 11: Micrograph of the control sample (as received) with EDS profile
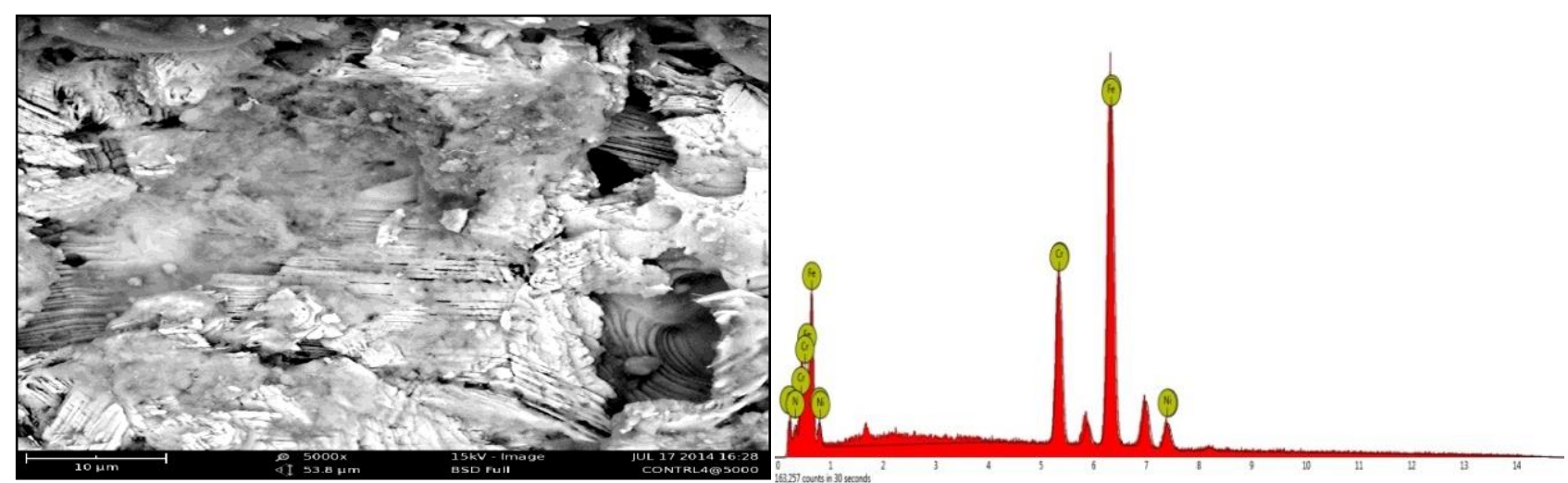

Figure 12: Micrograph of the control sample immersed in HCl for 40 days with EDS profile 


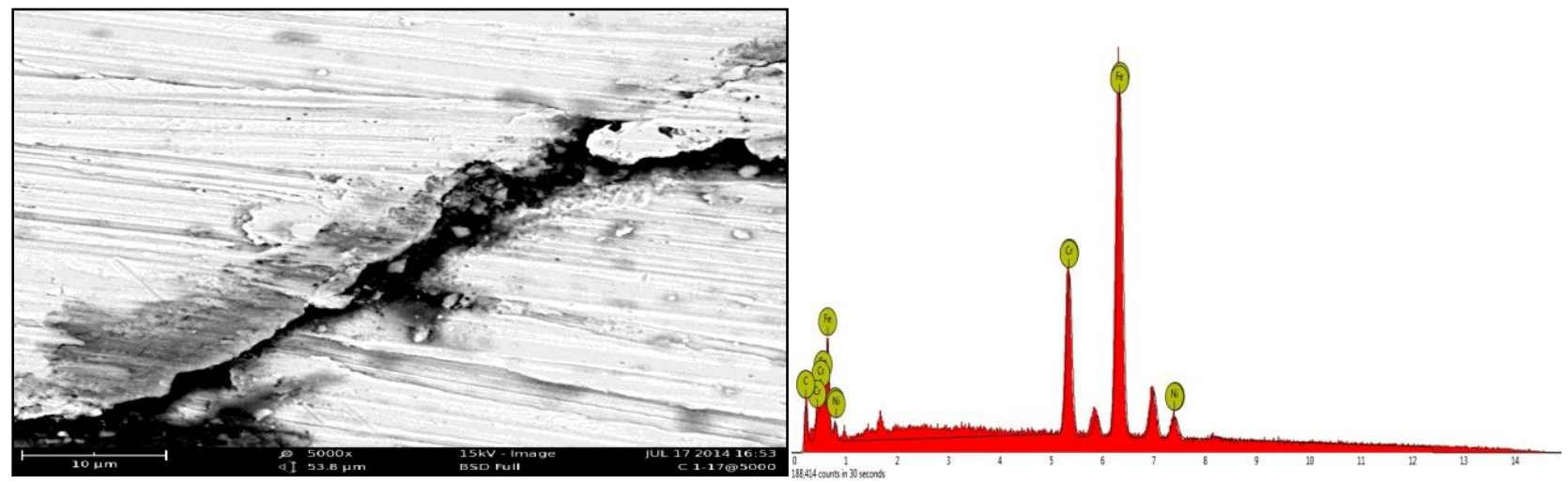

Figure 13: Micrograph of the HAZ of sample $C_{1}$ welded and immersed in HCl for 40 days with EDS profile.

\subsection{Scanning Electron Microscope of ASS Structure}

Figure 11 to 13 show the SEM micrographs of the samples of $5000 \mathrm{x}$ magnification with their respective EDS profiles indicating iron to have the highest percentage as the base metal followed by chromium as the highest alloy element. Figure 11 shows the SEM micrograph of as received sample of ASS (not welded and not immersed) with EDS profiles. It was observed here that the microstructure clearly showed a fine grain boundary and is an indication of a better blending of parent material and the alloying elements. The pore spaces observed in the microstructure suggest non uniformity of the ASS material.

Figure 12 shows signs of dissolution of metallic structure and grain boundaries due to the aggressiveness of chloride ion $\left(\mathrm{Cl}^{-}\right)$present in the medium. It was observed that $\mathrm{HCl}$ medium had higher corrosion attack on ASS at an exposure time of 40 days as compared to 16 days of exposure. Figure 13 show the SEM micrographs of the HAZ of sample $C_{1}$ welded and immersed for 40 days in $0.5 \mathrm{M}$ of $\mathrm{HCl}$ medium. It can be observed from the scanned image of the ASS sample $\mathrm{C}_{1}$ the crack propagation on the parent metal resulting in stress induced corrosion on the microstructure which arises as a result of internal stresses from non-uniform cooling during welding. This resulted to the poor tensile strength and hardness values of $\mathrm{C}_{1}$.

Microstructural analysis using SEM clearly show differences in the morphologies of the heat affected zone, fusion zone and the parts that are not affected, causing the grains of the heat affected zone to be more coarse than those of the unaffected zone (figure 11). The relationship between the microstructure and the properties of the welded ASS agrees with the conclusions of Mohanty, et al [20] and Madugu, et al [21]. These researchers showed that the grain size has a measurable effect on most of the mechanical properties such as hardness, tensile strength, impact strength and these properties increases as the grain size decreases.

\section{CONCLUSIONS}

The following conclusions can be drawn from this research:

i. The austenitic stainless steel grade 304 was used for this research to explore the different input process parameters on the micro-hardness, tensile strength and the impact of the weld samples.

ii. Design expert software (ANOVA) analysis was performed on the responses and it shows that current is the most significant parameters that influenced the micro-hardness, tensile strength and the impact of the weld.

iii. Experimental results indicate that tensile strength increased with increase in welding parameters from $120 \mathrm{MN} / \mathrm{m}^{2}$ to $133 \mathrm{MN} / \mathrm{m}^{2}$ at speed of $40 \mathrm{~cm} / \mathrm{min}$ and current of $110 \mathrm{~A}$.

iv. when the properties were compared with varying weld parameters adopted in joint's weld operations, there was a pattern displayed among the weld parameters with $\mathrm{C}_{3}$ for the micro-hardness, tensile strength and the impact of the weld (19.7HRA, $203 \mathrm{~N} / \mathrm{mm}^{2}$ and $19.7 \mathrm{~J}$ ) and $\mathrm{C}_{4}\left(14.9 \mathrm{HRA}, 189 \mathrm{~N} / \mathrm{mm}^{2}\right.$ and $14.9 \mathrm{~J}$ ) consistently coming out as the parameter producing an ASS weld joint with the best mechanical properties of hardness, tensile and impact strength.

v. The results obtained from the microstructure show that it has a delta ferrite structure in matrix of austenite in weld metal and the structure consists of austenite grains in heat affected zone as well as in parent metal.

\section{REFERENCES}

[1] Jason R Gas Metal Arc Welding Basics: Welding Current \& Welding Voltage. EWI publication. Retrieved from https://ewi.org/gas-metal-arcwelding-basics-welding-current-welding-voltage/ on $17^{\text {th }}$ February, 2017, 2015. 
[2] Gas Metal Arc Welding, Accessed from http://www.slideshare.net/asertseminar/gasmetal-arc-welding-gmaw on 17th February, 2017.

[3] Bassiouni, M.I.M. Evaluation of the Microstructure and Localized Corrosion Behaviour of AISI 2507 Super Duplex Stainless Steel Welds. A thesis submitted in partial fulfilment of the requirements for the degree of Master of Chemical Engineering, Published. 2012.

[4] Omiogbemi M. B. I Effects of Gas Metal Arc Welding Parameters on the Mechanical and Corrosion behaviour of Austenitic Stainless Steel in some Environments. Msc Thesis, Mechanical Engineering, Ahmadu Bello University, Zaria. May 2015.

[5] Seifedine, K.. European Journal of Scientific Research, ISSN 1450-216X Vol. 22 No.4, 2008, 508516, 2008.

[6] Sivashanmugam M. , Manoharan N. , Ananthapadmanaban D. and Ravi Kumar S. Investigation of Microstructure and mechanical properties of GTAW and GMAW joints on AA7075 Aluminium Alloy. International Journal on Design and Manufacturing Technologies, Vol.3, No.2, 67-62, 2009.

[7] Yan Jun, Gao Ming, Zeng Xiaoyan. Study microstructure and mechanical properties of 304 stainless steel joints by TIG, laser and laser-TIG hybrid welding, J Optics and Lasers in Eng 48 512517.2010.

[8] Gharibshahiyan E., Honarbakhsh A. R, Parvin N., Rehimian M. The effect of microstructure on hardness and toughness of low carbon welded steel using inert gas welding, J. Material and Design 2042-48,2011.

[9] Rani, B. E., Basu, B. B. Green inhibitors for corrosion protection of metals and alloys: An overview. Int. J. Corros. 2011 Sep 26; 2012. 2011.

[10] Avery, C. H. Heat Treatment of Stainless Steel. Metal Handbook, $8^{\text {th }}$ edition. America Society of Metals, Ohio, pp 200-243 1963.

[11] Parijslaan, R. Welding Stainless Steels: Techniques and Principles- An electronic Manual (www.cimeth.org $\backslash$ stainless.htm $).$ Retrieved $16^{\text {th }}$ March, 2013, 2002.
[12] James, G. K. Chronology of Corrosion Disasters. America Metal Society Handbook5, New York, NY, USA, 2000.

[13] Okibe, F. G. Preparation and Characterization of Activated Carbons from Brachystegia eurycoma and prosopis Africana Seed Hulls for Solid Phase Adsorption of Dyes. Ph.D Dissertation, Chemistry Department, $A B U$, Zaria, Nigeria, 2014.

[14] Yawas, D. S. Suitability assessment of some plant extracts and fatty acid vegetable oil as corrosive inhibitors. Ph.D Dissertation, Mechanical Engineering Department, ABU, Zaria, Nigeria, 2005.

[15] Ives, E., A Guide to wood micotermy; making quality microslides of wood sections, Ipswich, Suffolk IP8 3 $A Y, U K, 2001$.

[16] Mishra, S. C., Nayak. N. B and Satapathy, a. Investigation on Bio-waste Reinforced Epoxy Composites, Metallurgical and Materials Engineering Department, National Institute of Technology, Rourkela, India. pp 119-123,1999.

[17] Kock, J .W. Physical and Mechanical Properties of Chicken Feather Materials. Msc Thesis Presented to the Academic Faculty Georgia Institute of Technology, 2000.

[18].Claus, Q.J.. Stainless Steel and Corrosion. First edition, Damstahl. Retrieved on 25th September, 2014 from http://www.damstahl.com/Files/ Billeder/2011/PDF/BOOK/book.pdf .pp 81$\underline{84}, 2011$.

[19] Bonnefois, B., Charles, J.,Dupoiron, F. and Soulignac, P. (1991). How to Predict Welding Properties of Duplex Stainless Steels. In Duplex Stainless Steels . 1991.

[20] Mohanty, A. K., Misra M., and Drzal L.T., Sustainable Bio-composites from Renewable Resources: Opportunity and Challenges in the Green Materials World. Journal of Polymer nad Environment; 10:19-26, 2002.

[21] Madugu, I. A, Abdulwahab, M. and Aigbodion, V. S. Effect of Iron Filings on the Properties and Microstructure of Cast Fibre-Polyester/Iron Filings Particulate Composite. Journal of Alloys and Compounds, :808-811, 2010. 